\title{
A new simple whole blood flow cytometry-based method for simultaneous identification of activated cells and quantitative evaluation of cytokines released during activation
}

\author{
Arancha Rodríguez-Caballero, ${ }^{1,2, *}$, Andrés C García-Montero ${ }^{1,2, *}$, Clara Bueno ${ }^{1,2}$, \\ Julia Almeida ${ }^{1,2}$, Rudi Varro ${ }^{3}$, Roy Chen $^{3}$, Atanasio Pandiella ${ }^{2}$ and Alberto Orfao ${ }^{1,2}$ \\ ${ }^{1}$ Service of Cytometry, Department of Medicine; ${ }^{2}$ Cancer Research Center, University of Salamanca, \\ Salamanca, Spain and ${ }^{3}$ Becton Dickinson Biosciences, San José, CA, USA
}

\begin{abstract}
The multiple cellular and soluble elements of the immune system respond in a coordinated way, orchestrated by cytokines, to preserve the integrity of the organism. In this study, we describe a new and unique whole blood method that, with minimal sample manipulation, allows an overall evaluation of immune responses by simultaneously measuring cell activation and cytokine secretion. The identification of cells actively secreting cytokines is based on the stabilization of tumor necrosis factor $\alpha(T N F \alpha)$ at the cell surface through the use of a specific inhibitor of the TNF $\alpha$-converting enzyme. This inhibitor does not affect the release of cytokines other than TNF $\alpha$ and makes it possible to assess, in the same measurement, the phenotype of TNF $\alpha^{+}$-secreting cells and quantify multiple secreted cytokines by using a specific and highly sensitive flow cytometry-based bead immunoassay. Upon stimulation of normal peripheral blood samples with either phorbol 12-myristate 13 acetate (PMA) plus ionomycin or lipopolysaccharide (LPS), both the number of TNF $\alpha^{+}$cells and the amount of secreted cytokines progressively increased, the former becoming detectable first. After stimulation for $3 \mathrm{~h}$ with PMA plus ionomycin, cellular responses were associated with surface TNF $\alpha$ expression on the majority of $\mathrm{CD3}^{+} \mathrm{T}_{\text {cells }}$ and secretion of Th1-associated cytokines: interferon $\gamma$, interleukin (IL)-2, and to a lesser extent IL4. In turn, stimulation with LPS induced a response mainly by inflammatory cells. After $4 \mathrm{~h}$ of LPS-stimulation, the majority of $\mathrm{CD}_{14}{ }^{+}$monocytes showed surface TNF $\alpha$ expression; in parallel, high amounts of soluble IL1 $\beta$, IL6, and IL8 became detectable. Likewise, stimulation of blood samples with cytomegalovirus (CMV) lysates induced viralspecific immune responses detectable in seropositive but not seronegative volunteers; such responses were associated with the detection of increased numbers of TNF $\alpha^{+}$monocytes, $\mathrm{TNF} \alpha^{+} / \mathrm{CD8}{ }^{+}$T cells and TNF $\alpha^{+} / \mathrm{CD8}$ T lymphocytes in association with an increased secretion of IFN $\gamma$, IL6 and TNF $\alpha$.

Laboratory Investigation (2004) 84, 1387-1398, advance online publication, 16 August 2004; doi:10.1038/labinvest.3700162
\end{abstract}

Keywords: bead immunoassays; cell activation; cytokines; cytomegalovirus; flow cytometry; immune system; whole blood

Owing to the diversity of the cellular elements of the immune system, their wide distribution throughout the body and their mobility, immune responses require a complex coordinated network between

Correspondence: Professor A Orfao, $\mathrm{MD}, \mathrm{PhD}$, Centro de Investigación del Cáncer, Avda. Universidad de Coimbra $\mathrm{S} / \mathrm{N}$, Campus Miguel de Unamuno, 37007-Salamanca, Spain.

E-mail: orfao@usal.es

*The first two authors have equal contribution in this work and both are equally considered as 'first author'.

Received 29 March 2004; revised 9 June 2004; accepted 20 June 2004; published online 16 August 2004 different cell populations and soluble signalling elements. ${ }^{1}$ Secretion of cytokines and chemokines together with the expression of their receptors on the cellular membrane or into soluble forms, direct the immune response in a coordinated manner, by inducing various reactions, including activation and/or inhibition of specific populations of naïve, memory and effector cells. ${ }^{2}$

For many years, it is believed that cytokines play a central role in the homeostasis of the immune system and the coordination of immune responses. In fact, different patterns of cytokine secretion have been identified which induce specific types of 
responses. ${ }^{3}$ In recent decades, an increasingly high number of methods aimed at monitoring immune responses have been developed. At present, highlysensitive methods are available that allow the identification of cytokine secretion at the messenger RNA (mRNA) level either using 'bulk' Northern and PCR techniques ${ }^{4}$ or single-cell based, in situ hybridization approaches. ${ }^{5}$ Despite this, direct evaluation of protein secretion is usually preferred, ${ }^{6-11}$ because detection of specific mRNA does not assure secretion of the protein due to the translational regulation to which the synthesis of several cytokines is subjected. ${ }^{12}$ Protein production and secretion can be studied by quantitative immunospecific methods such as enzyme-linked immunosorbent assay (ELISA) and Western blot. ${ }^{4}$ Despite the high sensitivity and precision of these methods, none of them enables the simultaneous quantification of the cytokines produced or the identification and characterization of the secreting cells. In order to link cytokine secretion to the specific cell populations that produce them, new alternative approaches have been developed for identifying cytokine production at the single-cell level. Currently, the most representative techniques include the enzyme-linked immunosorbent spot assay (ELISPOT) ${ }^{4}$ and flow cytometry procedures for the detection of either intracellular ${ }^{13-15}$ or secreted cytokines captured and retained on the cell surface in an affinity matrix based on the use of bispecific (ie anti-CD45/anticytokine) antibody molecules. ${ }^{16}$ Although these methods enable determination of which cells are actually producing a specific cytokine, they typically require extensive sample manipulation including inhibition of protein secretion or the prevention of cytokine diffusion into the extracellular medium, thereby altering the natural cytokine network. In addition, these latter approaches do not allow for the simultaneous quantitative evaluation of the overall production of one or more cytokines.

In the present study, we describe a new and simple flow cytometry whole blood method that allows simultaneous identification of specific populations of cytokine-producing cells and quantification of the multiple cytokines secreted by these cells into the extracellular medium, in which sample manipulation is minimal. The approach described allows rapid evaluation of immunological responses against nonspecific and specific antigens both at the cellular and soluble levels.

\section{Materials and methods}

\section{Samples}

Heparin anticoagulated peripheral blood (PB) samples from a total of 45 adult volunteers were obtained after informed consent according to the guidelines of the Ethics Committee of the University Hospital of Salamanca (Salamanca, Spain). In all experiments, PB samples were prepared and cultured in vitro within a maximum period of $2 \mathrm{~h}$, after they were collected. Of these 45 samples, 12 were used for the evaluation of cytomegalovirus (CMV)-specific immune responses. From them, seven corresponded to normal healthy CMV-seropositive and five to CMV-seronegative donors. CMV-serostatus was determined by an immunoglobulin $G$ (IgG) and immunoglobulin $M$ (IgM) ELISA (VIDAS ${ }^{\mathbb{R}} \mathrm{CMV}$ IgG and VIDAS ${ }^{\mathbb{R}} \mathrm{CMV}$ IgM, Biomérieux, Marcy ÍEtoile, France). For stimulation purposes, PB samples were diluted 1:5 (vol:vol) in RPMI 1640 (Biowhittaker, Walkersville, MD, USA) containing 1\% (w/v) L-glutamine (Sigma, St. Louis, MO, USA), except for the 12 samples used for the evaluation of CMV-specific immune responses, which were diluted 1:2 (vol:vol).

\section{In Vitro Stimulation of Cytokine Production by PB Monocytes and T Lymphocytes}

RPMI 1640-diluted whole blood samples were aliquoted into tubes containing $250 \mu \mathrm{l}$ of the diluted sample either in the presence or the absence of $20 \mu \mathrm{mol} / \mathrm{l}$ of the BB3103 tumor necrosis factor (TNF)- $\alpha$-converting enzyme (TACE) inhibitor (kindly provided by British Biotechnology, Oxford, England). For stimulation purposes $0.1 \mu \mathrm{g} / \mathrm{ml}$ lipopolysaccharide (LPS) (SIGMA) or $0.025 \mu \mathrm{g} / \mathrm{ml}$ of phorbol 12-myristate 13 acetate (PMA) (SIGMA) plus $1 \mu \mathrm{g} / \mathrm{ml}$ of ionomycin (SIGMA) or $5 \mu \mathrm{g} / \mathrm{ml}$ of CMV whole lysate (Advanced Biotechnologies Inc., Columbia, MD, USA) were added, to induce cytokine secretion by $\mathrm{PB}$ monocytes and $\mathrm{T}$ lymphocytes. ${ }^{18-20}$ Additionally, in those samples $(n=12)$ used for the CMV-lysate stimulatory assays, purified costimulatory monoclonal antibodies (MAb) directed against CD28 and CD49d (Becton/Dickinson Biosciences (BDB), San Jose, CA, USA) were added at a final concentration of $1 \mu \mathrm{g} / \mathrm{ml}$ for optimal stimulation of T cells with various activation thresholds. ${ }^{17}$ The tubes were placed in a sterile environment, at $37^{\circ} \mathrm{C}$ in a $5 \% \mathrm{CO}_{2}$ humidified atmosphere and cultured for variable periods of time. LPSstimulated blood samples were harvested after $30 \mathrm{~min}, 1,2,3,4,5$ and $6 \mathrm{~h}$ of incubation, PMA plus ionomycin-stimulated samples were harvested after $30 \mathrm{~min}, 1,2,3$ and $4 \mathrm{~h}$ and CMV-stimulated samples were collected after $6 \mathrm{~h}$ of incubation, ${ }^{20}$ as described below in the Results section. In all experiments, an unstimulated sample aliquot was always processed in parallel, as a negative control.

\section{Quantification of Cytokines Secreted into the Culture Supernatants}

For the quantitative evaluation of cytokine secretion into the culture supernatants, $50 \mu \mathrm{l}$ of supernatant were collected at each of the time points indicated above. The Cytometric Bead Array immunoassay system $\left(\mathrm{CBA}^{\mathrm{TM}}, \mathrm{BDB}\right)$ was used to quantify either single cytokines-human interleukin (IL) $6(n=5)$, 
interferon $\gamma(\operatorname{IFN} \gamma)(n=5)$ and tumor necrosis factor $\alpha(\mathrm{TNF} \alpha)(n=6)$-or to assess simultaneously IFN $\gamma$, TNF $\alpha$, IL2, IL4, IL5 and IL10 (Human Th1/Th2 CBA kit; BDB)—on PMA/ionomycin-stimulated samples $(n=5), \mathrm{TNF} \alpha$, IL1 $\beta$, IL6, IL8, IL10, IL12 (inflammatory CBA kit; BDB)—on LPS-induced blood cell activation $(n=7)$ or IFN $\gamma, \operatorname{TNF} \alpha$, IL2, IL4, IL6 and IL10 (Human Th1/Th2 CBA kitII, BDB) or CMVlysate stimulatory assays $(n=12)$.

Briefly, $50 \mu \mathrm{l}$ of the supernatant were incubated at room temperature for $2 \mathrm{~h}$ (Th1/Th2 CBA kit and individual cytokines) or $3 \mathrm{~h}$ (Inflammatory CBA kit) with $50 \mu \mathrm{l}$ of anticytokine MAb-coated beads and with $50 \mu \mathrm{l}$ of the appropriate phycoerythrin (PE)conjugated anticytokine antibody detector. After this incubation period, samples were washed once $(5 \mathrm{~min}$ at $200 \mathrm{~g}$ ) in order to remove the excess of detector antibodies. Immediately afterwards, data acquisition was performed on a FACSCalibur flow cytometer (BDB) equipped with an argon ion laser and a red diode laser, using the CellQUEST ${ }^{\mathrm{TM}}$ software program (BDB); information was stored for at least 300 events corresponding to each bead population analyzed per sample. In all cases, light scatter parameters were collected using a four-decade logarithmic amplification mode, following the recommendation of the manufacturer. For data analysis, both the Paint-AGate and the Cytometric Bead Array (CBA) software programs (BDB) were used. During analysis, the mean fluorescence intensity (MFI) value for the PEassociated fluorescence was recorded for each population of cytokine capture-beads.

To allow quantification of the captured cytokines, standard curves were developed using cytokine standards. Standard curves were plotted (cytokine calibrator concentration vs mean PE fluorescence intensity) using a four-parameter logistic curve fitting model (BD CBA software). A total of 12 standards for each cytokine were used at concentrations ranging from 0 to $10000 \mathrm{pg} / \mathrm{ml}$. Concentration of the cytokine in the sample supernatant was considered to be directly proportional to the mean fluorescence intensity of the corresponding bead population measured in fluorescence channels (relative linear arbitrary units scaled from 0 to $10^{4}$ ). The specific concentration of each cytokine analyzed was determined through the comparison of the MFI of unknown samples to the standard curve.

\section{Simultaneous Identification of Cell Activation and Quantification of Secreted Cytokines}

For the simultaneous identification of cytokineproducing cells and the quantification of secreted cytokines, a total of five PB samples, stimulated as described above with either LPS or PMA plus ionomycin plus $12 \mathrm{~PB}$ samples stimulated with CMV-whole lysate were used. Amounts of $50 \mu \mathrm{l}$ of the stimulated samples were harvested at the time periods listed above and immediately incubated at room temperature for $2 \mathrm{~h}$ (PMA plus ionomycin or CMV-stimulated samples) or $3 \mathrm{~h}$ (LPS-stimulated samples) with $50 \mu \mathrm{l}$ of the appropriate cytokinecapture bead populations and the appropriate mixture of PE-conjugated detector antibodies. At $15 \mathrm{~min}$ prior to the end of this incubation period, cell surface stainings were performed by adding either $10 \mu \mathrm{l}$ of anti-CD14-FITC (MфP9, BDB), $3 \mu \mathrm{l}$ of anti-TNF $\alpha$-PE (MAb11, BDB) and $10 \mu \mathrm{l}$ of antiCD45-PC5 diluted 1/10 in phosphate-buffered saline (PBS) (J33 MAb, Immunotech, Marseille, France) to LPS-stimulated samples or $10 \mu \mathrm{l}$ of anti-CD3-FITC (HIT3a, BDB) plus $3 \mu \mathrm{l}$ of anti-TNF $\alpha-\mathrm{PE}, 10 \mu \mathrm{l}$ of antiCD45-PC5 and $10 \mu \mathrm{l}$ of anti-CD4-APC (SK3, BDB) or anti-CD8 APC (B9.11, Immunotech) to either PMA/ ionomycin- or CMV-stimulated samples, respectively. Prior to data acquisition, the sample containing both the stained cells and the cytokine-capture bead mixture was centrifuged (200 g, $5 \mathrm{~min}$ ) and resuspended in $300 \mu \mathrm{l}$ of PBS.

Absolute counts for each of the different subsets of PB leukocytes were calculated after adding known numbers of antibody-coated beads to each tube by reverse-pipetting, according to well-established methods. $^{21}$

In all LPS- or PMA plus ionomycin-stimulated samples, soluble cytokine levels were also measured on the culture supernatant containing the plasma of the same stimulated specimen using the same cytokine-capture beads according to the instructions of the manufacturer, as described above. In order to make comparable the results of soluble cytokine measurements in culture supernatants and RPMIdiluted whole blood samples, the latter was corrected according to the haematocrite.

Data acquisition was performed on a FACSCalibur flow cytometer, collecting information about between $5 \times 10^{4}$ and $1.5 \times 10^{5}$ cells. Unstimulated samples were analyzed to verify the effect of the stimulation. Evaluation of cytokine production was based on percentage of positive cells, after subtracting the percentage of cells staining above the threshold for positivity in the negative control.

\section{Cell Staining for Intracellular Cytokines}

Intracytoplasmic detection of $\mathrm{TNF} \alpha$ production by PB lymphocytes and monocytes was performed in those 12 PB used to evaluate CMV-specific immune responses. After culturing $250 \mu \mathrm{l}$ of RPMI diluted (1:2, vol:vol) PB for $2 \mathrm{~h}$ in the presence of $5 \mu \mathrm{g} / \mathrm{ml}$ of CMV whole lysate and the anti-CD28 and antiCD49d costimulatory MAbs, $10 \mu \mathrm{g} / \mathrm{ml}$ of brefeldin A (BFA; Sigma) was added to each tube. Then cells were incubated for $4 \mathrm{~h}$ more. Afterwards, $10 \mu \mathrm{l}$ of anti-CD3-FITC, $10 \mu \mathrm{l}$ of anti-CD45-PC5, and $3 \mu \mathrm{l}$ of CD8-APC were added and the cells were incubated for $15 \mathrm{~min}$ at room temperature in darkness. Immediately after this incubation period, cells were fixed, permeabilized and stained with $3 \mu \mathrm{l}$ of anti- 
TNF $\alpha$-PE MAb, using the Fix \& Perm reagent (Caltag Laboratories, San Francisco, CA, USA). Finally, cells were washed once in $2 \mathrm{ml}$ of PBS ( $5 \mathrm{~min}$ at $540 \mathrm{~g}$ ) and resuspended in $0.5 \mathrm{ml}$ of PBS for data acquisition in a FACS-Calibur flow cytometer, as described above. Unstimulated samples were analyzed to verify the effect of the stimulation. Evaluation of cytokine production was based on percentage of positive cells, after subtracting the percentage of cells staining above the threshold for positivity in the negative control.

\section{Recovery Experiments}

Recovery experiments were performed in parallel on five different unstimulated RPMI-1640-diluted (1/5, vol:vol), IFN $\gamma$-free, normal PB samples and their corresponding plasmas. For that purpose, precisely defined amounts of IFN $\gamma \quad(1250$ and $5000 \mathrm{pg} / \mathrm{ml})$ were added in parallel to each blood and plasma paired samples. Measurement of the spiked cytokine from the two sample types (RPMI-diluted blood and plasma supernatant) was performed by incubating a mixture of a volume of $50 \mu \mathrm{l}$ of IFN $\gamma$-spiked sample and $50 \mu \mathrm{l}$ of a solution containing beads coated with an anti-IFN $\gamma$ monoclonal antibody (kindly provided by BDB) under the same conditions as those described above for the quantitative evaluation of soluble cytokines in culture supernatants.

\section{Statistical Methods}

Median and mean values and their standard deviations, as well as range, were calculated for each variable under study using the SPSS software (version 10.0; SPSS, Chicago, IL, USA). The statistical significance of the differences observed between groups was assessed using either the nonparametric Friedman and Wilcoxon tests for paired samples or the nonparametric Mann-Whitney $U$-test for unpaired samples (SPSS 10.0 software); $P$-values $<0.05$ were considered to be associated with statistically significant differences.

\section{Results}

Simultaneous Analysis of TNF $\alpha^{+}$-Activated Cells and a Secreted Cytokine Captured on Antibody-Coated Beads

By setting a threshold on red fluorescence (FL3 parameter in the flow cytometer instrument used), a clear discrimination could be achieved in whole blood samples between beads and $\mathrm{CD}_{4} 5^{+}$leukocytes on one side, and CD45 ${ }^{-}$red cells and platelets on the other (Figure 1a). Bead particles and leukocytes showed different light scatter characteristics, which further allowed specific discrimination between them and simultaneous identification of beads and leukocytes as illustrated in Figure 1b. The feasibility of analyzing further stainings separately on specific leukocyte subsets and cytokine-capture beads in either unstimulated or stimulated nonlysed-nonwashed whole blood samples is illustrated in Figure 1, in panels c-f. Stimulation of PB with either LPS, in the presence of IL6 capture beads (Figure 1d) or with PMA plus ionomycin, in the presence of IFN $\gamma$ capture beads (Figure 1f), was associated with a significant increase in the PEassociated fluorescence of the capture beads due to secretion of IL6 (Figure 1d) and IFN $\gamma$ (Figure 1f), respectively, as compared to nonstimulated paired samples treated under identical conditions (Figure 1c and e, respectively). Simultaneously, the subsets of leukocytes showed accumulation of TNF $\alpha$ on the cell surface membrane; these cells corresponded to $\mathrm{CD} 14^{+}$monocytes in LPS-stimulated samples (Figure 1d) and $\mathrm{CD}^{+} \mathrm{T}$ cells in PMA plus ionomycin-activated cell cultures (Figure 1f).

\section{Kinetic Analysis of Immune Responses to LPS and PMA Plus Ionomycin through the Simultaneous Measurement of $\mathrm{TNF}^{+}$-Cytokine-Secreting Cells and Quantification of Soluble Amounts of Secreted Cytokines}

In order to evaluate the kinetics of the effect of the BB3103 inhibitor on $\mathrm{TNF} \alpha$ secretion by PB leukocytes stimulated with either LPS or PMA plus ionomycin, sequential analysis of $\mathrm{TNF} \alpha$ secretion in the presence or absence of BB3103 was performed. As shown in Table 1, the BB3103 compound showed an effectiveness of between 90 and $95 \%$ during the period of time analyzed (between $30 \mathrm{~min}$ and $6 \mathrm{~h}$, after stimulation).

$\mathrm{TNF} \alpha^{+}$monocytes were already present at detectable numbers after $30 \mathrm{~min}$ of stimulation with LPS (Figure 2a), whereas secreted IL6 soluble levels could only be detected in the same sample aliquots after $2 \mathrm{~h}$ of culture (Figure 2b). Since $\mathrm{TNF} \alpha^{+}$ monocytes were first detected, their relative number progressively increased till the last time-point analyzed (6h) (Figure 2a); at the same time, soluble amounts of IL6 also increased progressively. As shown in Figure 2b, no significant differences were observed between the amount of soluble IL6 detected in whole blood and the corresponding plasma samples, at any time-point analyzed.

Kinetic analysis of the T-cell response in whole blood samples stimulated with PMA plus ionomycin was performed through the simultaneous enumeration of $\mathrm{TNF} \alpha^{+} \mathrm{T}$ cells and quantification of soluble amounts of secreted IFN $\gamma$. As shown in Figure 2c and $\mathrm{d}, \mathrm{TNF} \alpha^{+} \mathrm{T}$ cells and soluble IFN $\gamma$ levels were already detectable $30 \mathrm{~min}$ and $1 \mathrm{~h}$ after stimulation, respectively. Thereafter, both the percentage of $\mathrm{TNF} \alpha^{+} \mathrm{T}$ cells and the amount of soluble IFN $\gamma$ progressively increased till the last time-point analyzed (4h) (Figure 2c and d). In contrast to what occurred with the measurement of soluble amounts 

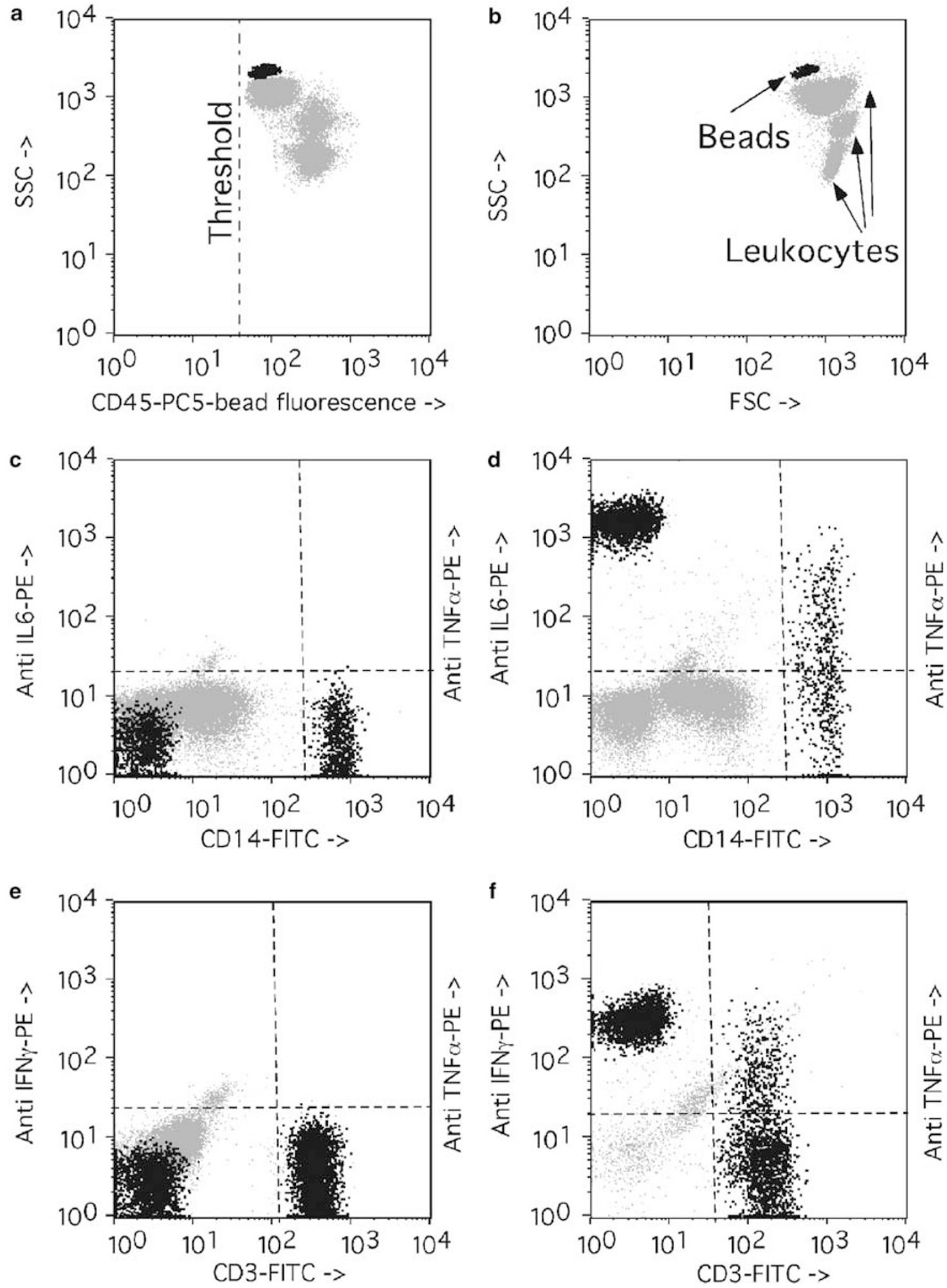

Figure 1 Representative bivariate dot plots of experiments in which assessment of TNF $\alpha$ expression on activated cells and quantitation of soluble cytokines captured on beads were simultaneously performed. Dot plot a shows how the threshold was set to distinguish events corresponding to either beads or $\mathrm{CD} 45^{+}$leukocytes from other events. In panel bo events corresponding to beads were specifically distinguished (black dots) from those representing CD45 ${ }^{+}$cells (gray dots) on the basis of their higher sideward (SSC) and forward (FSC) light scatter properties. Plots $\mathbf{c}$ and $\mathbf{d}$ show a simultaneous staining for IL6 capture beads (black dots in the left side of both plots) and $\mathrm{TNF} \alpha$ on $\mathrm{CD}_{14}{ }^{+}$monocytes (black dots in the right side of the two plots) from a peripheral blood sample mixed with the BB3103 compound and cultured for $4 \mathrm{~h}$ either in the absence (panel c) or in the presence of $0.1 \mu \mathrm{g} / \mathrm{ml}$ of LPS (panel d). In the lower two panels, simultaneous stainings for IFN $\gamma$ on beads (black dots in the left side of both plots) and TNF $\alpha$ on CD3 ${ }^{+}$T cells (black dots in the right side of both plots) from a peripheral blood sample mixed with the BB3103 compound and cultured for $3 \mathrm{~h}$ either in the absence (panel e) or in the presence of PMA $(0.025 \mu \mathrm{g} / \mathrm{ml})$ plus ionomycin $(1 \mu \mathrm{g} / \mathrm{ml})$, are shown. 
Table 1 Kinetic analysis of the effect of the BB3103 TACE inhibitor on TNF $\alpha$ secretion by PB leukocytes stimulated with either LPS or PMA plus ionomycin

\begin{tabular}{|c|c|c|c|c|c|c|}
\hline \multirow[t]{2}{*}{ Time $(h)$} & \multicolumn{3}{|c|}{ Soluble $T N F \alpha$ levels in $L P S$-stimulated $P B$} & \multicolumn{3}{|c|}{ Soluble $T N F \alpha$ levels in $P M A+$ ionomycin-stimulated $P B$} \\
\hline & Without BB3103 (pg/ml) & With BB3103 (pg/ml) & $\%$ Inhibition & Without BB3103 (pg/ml) & With BB3103 (pg/ml) & $\%$ Inhibition \\
\hline 2 & NA & NA & NA & $4770 \pm 2223$ & $320 \pm 145$ & $92 \pm 2$ \\
\hline 3 & $1289 \pm 534$ & $54 \pm 31$ & $96 \pm 3$ & $8260 \pm 2631$ & $756 \pm 261$ & $89 \pm 10$ \\
\hline 4 & $4315 \pm 1383$ & $273 \pm 112$ & $93 \pm 4$ & $10909 \pm 3475$ & $1247 \pm 770$ & $89 \pm 4$ \\
\hline 5 & $6250 \pm 2154$ & $538 \pm 151$ & $91 \pm 3^{*}$ & NA & NA & NA \\
\hline 6 & $7553 \pm 2171$ & $722 \pm 181$ & $90 \pm 2 *$ & NA & NA & NA \\
\hline$P$-value & $0 . \overline{00} 01$ & 0.0001 & 0.03 & 0.006 & 0.03 & 0.51 \\
\hline
\end{tabular}

Results are expressed as mean \pm standard deviation values. NA: not analyzed.

${ }^{*}$ Statistically significant differences $(P<0.05)$ found in comparison with the percent inhibition observed at $3 \mathrm{~h}$.
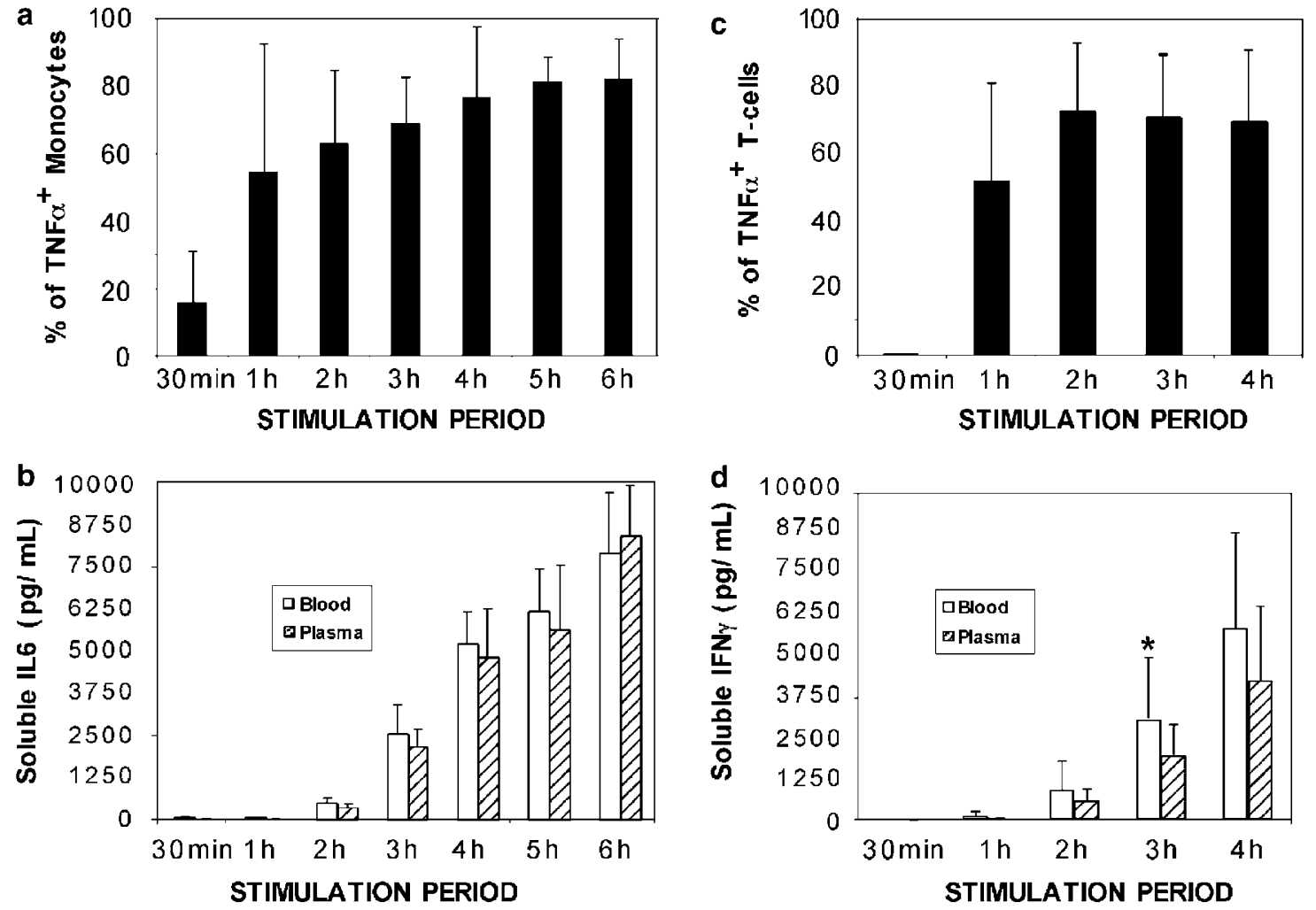

Figure 2 Kinetic analysis of both CD14 ${ }^{+}$monocyte and CD3 ${ }^{+}$T-cell responses after stimulation of PB samples $(n=5)$ with LPS (panels a and $\mathbf{b}$ ) or PMA plus ionomycin (panels $\mathbf{c}$ and $\mathbf{d}$ ) for different time periods. In panels $\mathbf{b}$ and $\mathbf{d}$ the amount of secreted IL-6 (pg/ml) and IFN $\gamma$ (pg/ml) in paired blood and plasma samples, are shown, respectively. Panels a and c show the percentage of TNF $\alpha$-secreting monocytes after stimulation with LPS (panel a) and TNF $\alpha$-secreting T lymphocytes after PMA plus Ionomycin stimulation (panel c) at different times in culture. *Statistically significant differences were found between IFN $\gamma$ levels in blood and plasma after $3 \mathrm{~h}$ of incubation with PMA plus ionomycin $(P<0.05)$.

of IL6 after stimulation with LPS, quantification of soluble IFN $\gamma$ from paired blood and plasma samples after stimulation with PMA plus ionomycin provided different results. Accordingly, blood levels of soluble IFN $\gamma$ were constantly higher than the plasmatic ones (Figure 2d), differences reaching statistical significance at $3 \mathrm{~h}$ after stimulation. In order to compare the precision of the measurements performed in both types of samples, recovery experiments in which known amounts of IFN $\gamma$ were spiked into IFN $\gamma$-free paired blood and plasma samples, were performed. As shown in Table 2, blood measurements showed both a better recovery and a better precision than those performed on the plasma samples.

\section{Simultaneous Analysis of the Activation of Multiple Cell Subsets and Quantification of Secretion of Multiple Soluble Cytokines in Response to LPS and PMA Plus Ionomycin}

Based on the results of the kinetic studies described above, for those experiments aimed at the simulta- 
neous detection of $\mathrm{TNF} \alpha$-secreting cells and the quantification of multiple soluble cytokines produced, the time-points for the evaluation of responses to LPS and PMA plus ionomycin were set at 4 and $3 \mathrm{~h}$ after stimulation, respectively. Accordingly, in the same sample tube, we could simultaneously identify LPS-responding $\mathrm{CD} 14^{+}$monocytes and quantify the levels of several different inflammatory cytokines produced in the extracellular medium. In a similar manner, we could also identify $\mathrm{TNF} \alpha^{+}$cells in response to PMA plus ionomycin within different subsets of T cells (CD3 + CD4- or CD3 + CD4 +) and, at the same time, quantify the soluble levels of different cytokines they released, through the use of a mixture of different populations of cytokine-specific capture-beads (Figure 3a and b).
Table 2 Recovery of spiked IFN $\gamma$ into paired whole blood and plasma samples $(n=5)$

\begin{tabular}{lcc}
\hline & \multicolumn{2}{c}{ Amount of IFN $\mathrm{spiked}$ into the sample } \\
\cline { 2 - 3 } & $1250(\mathrm{pg} / \mathrm{ml})$ & $5000(\mathrm{pg} / \mathrm{ml})$ \\
\hline Recovered $\mathrm{IFN} \gamma(\mathrm{pg} / \mathrm{ml})$ & $(\%$ recovered $)$ & \\
Blood & $1206 \pm 99(96 \pm 8)$ & $4859 \pm 315(97 \pm 6)$ \\
Plasma & $905 \pm 148(72 \pm 12)$ & $3284 \pm 626(66 \pm 13)$ \\
$P$-value & 0.04 & 0.04 \\
\hline
\end{tabular}

Results are expressed as the mean amount of $\mathrm{IFN} \gamma \pm$ standard deviation (the percentage of spiked cytokine recovered is shown in brackets).
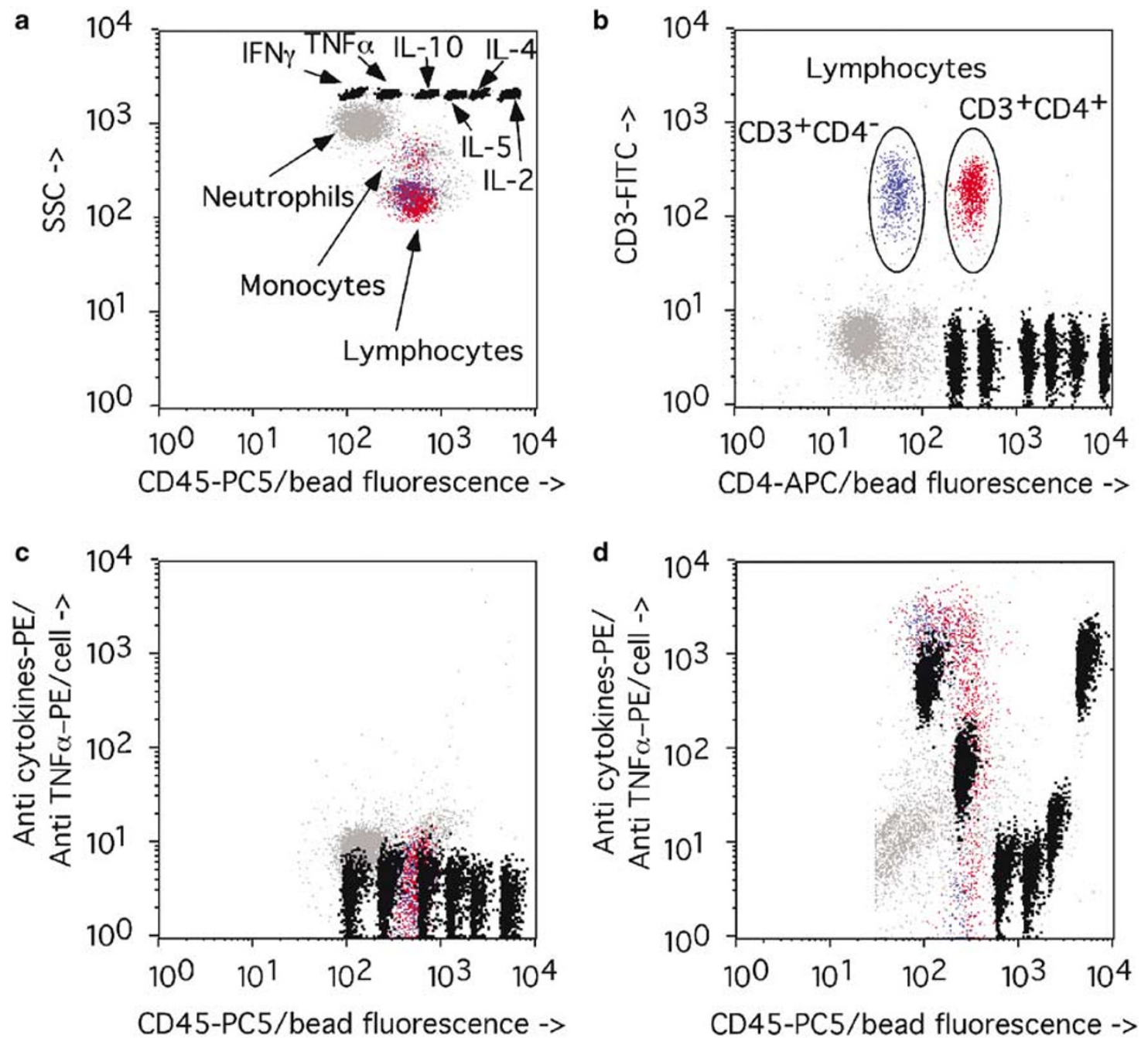

Figure 3 Representative bivariate dot plots of an experiment in which assessment of TNF $\alpha$ expression on activated $\mathrm{T}$ cells and quantitation of multiple soluble cytokines (IFN $\gamma, \mathrm{TNF} \alpha$, IL2, IL4, IL5 and IL10) captured on cytokine specific populations of beads, were simultaneously performed. Panel a illustrates how the different bead populations were identified based on their intrinsically distinct red fluorescence (black dots). Panel $\mathbf{b}$ shows how the two major CD3 ${ }^{+} / \mathrm{CD} 4^{+}$(red dots) and $\mathrm{CD}^{+} / \mathrm{CD}^{-}$(blue dots) $\mathrm{T}$ cell subsets were identified. In the lower two panels, the amount of secreted cytokines captured in their specific cytokine-capture bead population (black dots) and the amount of TNF $\alpha$ expressed on the surface of both CD3 ${ }^{+} / \mathrm{CD} 4^{+}$(red dots) and $\mathrm{CD} 3^{+} / \mathrm{CD}^{-}{ }^{-} \mathrm{T}$ cells are shown for the same PB sample cultured for $3 \mathrm{~h}$ in the absence (panel c) or the presence of PMA $(0.025 \mu \mathrm{g} / \mathrm{ml})$ plus ionomycin $(1 \mu \mathrm{g} / \mathrm{ml})$ (panel d). Events corresponding to CD3- $\mathrm{PB}$ non-T-cell leukocytes are depicted as gray events in all four dot plots. 
LPS stimulation of blood cells induced TNF $\alpha$ expression on cytokine-secreting monocytes $(77 \pm 21 \%)$ together with production into the extracellular medium of similar amounts of IL1 $\beta$ $(4247 \pm 2368 \mathrm{pg} / \mathrm{ml}), \quad$ IL6 $\quad(3390 \pm 762 \mathrm{pg} / \mathrm{ml}), \quad$ IL8 $(3664 \pm 1241 \mathrm{pg} / \mathrm{ml}$ ) (Figure $4 \mathrm{a})$, as well as $\mathrm{TNF} \alpha$ $(273 \pm 112 \mathrm{pg} / \mathrm{ml})$. As shown in Figure 3 , after $3 \mathrm{~h}$ of stimulation with PMA plus ionomycin, both $\mathrm{CD} 4^{+}$/ $\mathrm{TNF} \alpha^{+}$and $\mathrm{CD} 4^{-} / \mathrm{TNF} \alpha^{+}$T cells could be detected, representing $82 \pm 11$ and $82 \pm 5 \%$ of all $\mathrm{CD}^{+}$and $\mathrm{CD} 4^{-} \mathrm{T}$ cells. Such response was associated with production in the culture supernatant of detectable levels of Th1 cytokines (IFN $\gamma: 3747 \pm 1727 \mathrm{pg} / \mathrm{ml}$; TNF $\alpha: 223 \pm 127 \mathrm{pg} / \mathrm{ml}$; and IL2: $1163 \pm 381 \mathrm{pg} / \mathrm{ml}$ ) as well as low levels of IL4 $(50 \pm 22 \mathrm{pg} / \mathrm{ml})$ in the absence of other Th2 cytokines (undetectable amounts of IL-5 and IL-10) (Figure 4b).

\section{Simultaneous Analysis of the Activation of Multiple Cell Subsets and Quantification of Secretion of Multiple Soluble Cytokines in Response to CMV}

After stimulation with a CMV lysate, both $\mathrm{TNF} \alpha^{+}$ monocytes and $\mathrm{TNF} \alpha^{+} \mathrm{T}$ cells became detectable. The percentage of both $\mathrm{TNF} \alpha^{+}$monocytes and $\mathrm{TNF} \alpha^{+} \mathrm{T}$ cells was similar once $\mathrm{TNF} \alpha$ was detected at the cytoplasmic level after inhibiting protein secretion with brefeldin A or it was measured at the cell surface with the use of the TACE inhibitor:

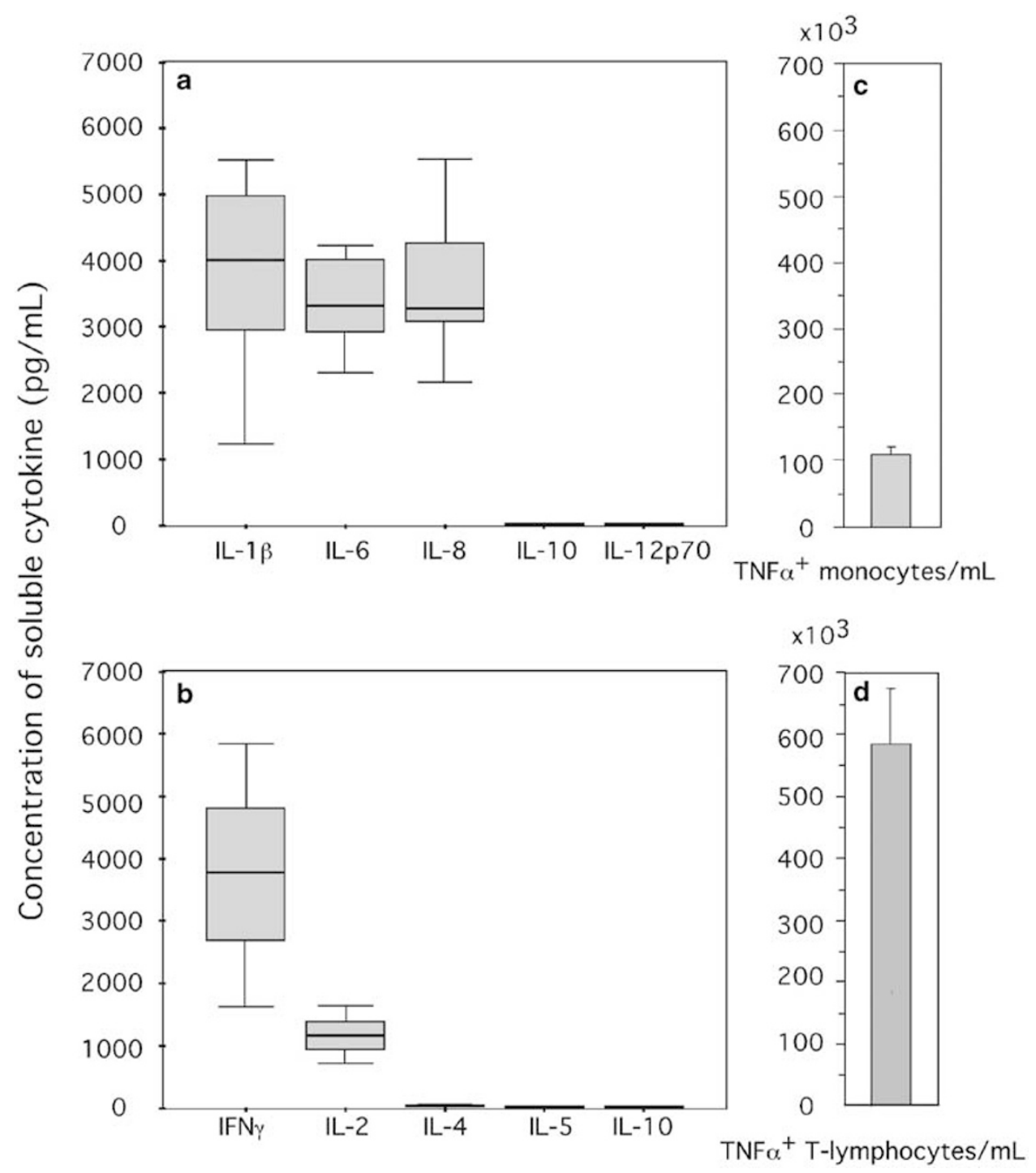

Figure 4 Total amount of soluble cytokines secreted by PB cells $(n=5)$ stimulated with either $0.1 \mu \mathrm{g} / \mathrm{ml}$ of LPS (panel a) or $0.025 \mu \mathrm{g} / \mathrm{ml}$ of PMA plus $1 \mu \mathrm{g} / \mathrm{ml}$ of ionomycin (panel b) after 4 and $3 \mathrm{~h}$ of culture, respectively. Panels $\mathbf{c}$ and $\mathbf{d}$ show the number of TNF $\alpha^{+}$monocytes and $\mathrm{TNF} \alpha^{+}$T cells present in the same samples after stimulation with LPS or PMA plus ionomycin, respectively. Boxes extend from the 25th to the 75th percentiles; the line in the middle and the vertical lines represent median values and 95\% confidence intervals, respectively. 

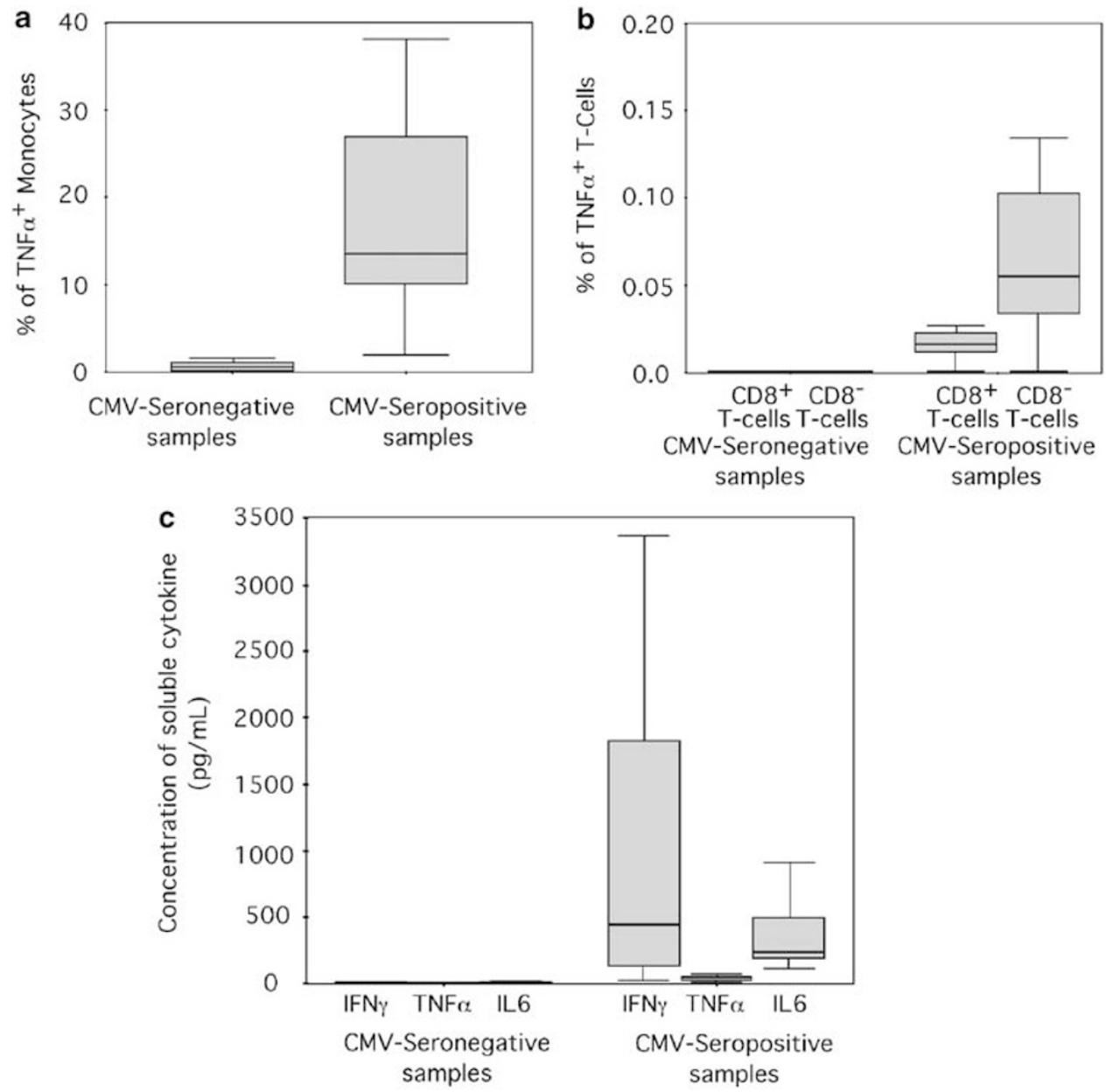

Figure 5 Comparative analysis of the PB monocyte and T-cell responses after $6 \mathrm{~h}$ of stimulation with CMV lysate in the presence of the BB3103 TACE inhibitor, in CMV-seropositive $(n=7)$ and CMV-seronegative $(n=5)$ volunteers. The two upper panels show the percentage of $\mathrm{TNF} \alpha^{+}$monocytes (panel a) and of $\mathrm{TNF} \alpha^{+} / \mathrm{CD} 8^{+}$and $\mathrm{TNF} \alpha^{+} / \mathrm{CD} 8^{-} \mathrm{T}$ cells (panel $\mathbf{b}$ ) from total monocytes and $\mathrm{T}$ cells, respectively. The lower panel (panel c) shows the soluble concentrations of secreted cytokines by TNF $\alpha^{+}$-cytokine secreting monocytes and T cells. Boxes extend from the 25th to the 75th percentiles; the line in the middle and the vertical lines represent median values and $95 \%$ confidence intervals, respectively.

median number of $\mathrm{TNF} \alpha^{+}$monocytes of 2.4 vs $11 \%$ (range: $1.5-3.4$ vs $1.8-18 \%$, respectively; $P=0.5$ ); of $\mathrm{TNF}^{+} \mathrm{CD8}^{+} \mathrm{T}$ cells, 0.01 vs $0.01 \%$; (range $0-0.03$ vs $0-0.02 \%$, respectively; $P=0.14)$, and of $\mathrm{TNF} \alpha^{+} \mathrm{CD}^{-} \mathrm{T}$ cells of 0.03 vs $0.03 \%$; range $(0-0.3$ vs $0-0.05 \%$, respectively; $P=0.27$ ). As shown in Figure 5, after $6 \mathrm{~h}$ of stimulation with CMV lysate, higher percentages of $\mathrm{TNF}^{+}$monocytes were observed in CMV-seropositive donors as compared with CMV-seronegative individuals $(18 \pm 14$ vs $0.6 \pm 0.6 \%, P=0.004)$. Likewise, the percentages of both $\mathrm{TNF} \alpha^{+} \mathrm{CD}^{-}(0.14 \pm 0.22$ vs $0 \pm 0 \%, P=0.009)$ and $\mathrm{TNF}^{+} \mathrm{CD}^{+}(0.03 \pm 0.04$ vs $0 \pm 0 \%, P=0.009)$ T-lymphocytes was also higher in CMV-seropositive samples. Additionally, as might be expected, the soluble concentrations of secreted IFN $\gamma$ (1105 \pm 1296 vs $3.3 \pm 5.6 \mathrm{pg} / \mathrm{ml} ; P=0.007), \mathrm{TNF} \alpha(42 \pm 39$ vs $\quad 0 \pm 0 \mathrm{pg} / \mathrm{ml} ; \quad P=0.003), \quad$ IL-6 $\quad(371 \pm 319$ vs $24 \pm 48 \mathrm{pg} / \mathrm{ml} ; P=0.007)$ were equally higher in $\mathrm{CMV}$-seropositive as compared to CMV-seronegative samples. In contrast, virtually no secretion of IL10 and IL4 was detected in both groups of individuals.

\section{Discussion}

In recent years, important advances have been achieved in the understanding of the immune system and its involvement in the development, progression and control of an increasingly high number of disease conditions. ${ }^{22,23}$ In addition, new preventive and curative therapies have been developed and assayed, which are based on the modulation of the status of the immune system and of immune responses, ${ }^{24}$ including vaccination trials against infectious agents (ie HIV) or tumors (ie melanomas). ${ }^{25,26}$ Owing to this, an increasingly high demand exists for immune monitoring approaches. Such immune monitoring procedures should ideally be able to detect specific qualitative and quantitative 
changes at both the cellular and soluble levels, in the absence of extensive ex vivo or in vitro sample manipulation.

In the present study, we describe a new and simple flow cytometry-based method for the overall evaluation of immune responses at both the cellular and soluble levels. The reported technique is specifically aimed at the simultaneous immunophenotypic identification and enumeration of cytokinesecreting cells and the quantification of multiple cytokines secreted by these cells into the extracellular medium. As shown, this method could be applied to the direct analysis of immune responses in whole blood specimens reducing sample manipulation and fractioning to a minimum.

In order to identify cytokine-secreting cells in the absence of extensive sample manipulation, the use of specific markers expressed at the cell surface level is preferred over intracellular markers. Once produced, cytokines are rapidly released into the extracellular medium, which prevents their detection both intracellularly and on the cytoplasmic membrane, unless stabilization procedures are employed. Most commonly, inhibitors of intracellular transport such as brefeldin A and monensin are used to induce intracellular accumulation of cytokines until immunophenotypically detectable amounts are obtained. ${ }^{13-15}$ However, such approaches require extensive sample manipulation for the detection of the synthesized cytokines, including cell fixation and permeabilization procedures. In the 1990s, Manz et a ${ }^{16}$ described a method based on the use of bispecific (CD45/cytokine) monoclonal antibodies, which allowed capture of specific cytokines on the cell surface as soon as they had been produced. However, such approach requires extensive dilution of the sample in order to avoid proximity between cells that could give rise to false positive results due to the capture of cytokines by $\mathrm{CD} 45^{+}$cells adjacent to the secreting cells. More recently, we have shown that in vitro stimulation of cytokine secretion in the presence of highly specific inhibitors of TACE, was associated with a progressive accumulation of detectable amounts of TNF $\alpha$ on the cell surface at the cytoplasmic membrane; interestingly, the amount of $\mathrm{TNF} \alpha$ stabilized at the cell surface was similar to that accumulated at the intracellular level once inhibitors of intracellular transport (ie brefeldin A) were used in parallel for both LPS- and PMA plus ionomycin-stimulated cells. ${ }^{27}$ An additional advantage of this approach is that it does not directly interfere with other cell functions such as antigen presentation. In the present study, we confirm and extend these observations by showing that the BB3103 compound inhibits between 90 and $95 \%$ of all TNF $\alpha$ secreted by either LPS-stimulated PB monocytes or PMA plus ionomycin-activated $\mathrm{CD}^{+}{ }^{+} \mathrm{T}$ cells. Such inhibitory effect remains relatively stable for up to several hours; in addition, it allowed detection of small numbers of $\mathrm{TNF} \alpha$-secreting cells in the context of antigen-specific immune responses with a similar efficiency than conventional flow cytometry assays used for the detection of secreted cytokines at the intracytoplasmic level, as proven for the CMVstimulatory model assayed here.

$\mathrm{TNF} \alpha$ is one of the most ubiquitous and earliest cytokines to be secreted. ${ }^{28}$ In addition, most cytokine-secreting cells also produce $\mathrm{TNF} \alpha^{13,29-33}$ that makes it a good candidate as a universal marker to be used for the identification of cytokine-secreting cells. Up till now, the most commonly used cell surface marker to detect recently activated lymphocytes and other immune cells has been CD69. ${ }^{34-36}$ Although no direct comparison between the two markers has been performed, data from the literature indicate that CD69 could be far less specific than $\mathrm{TNF} \alpha$, because a significant proportion of CD69 ${ }^{+}$ cells do not produce cytokines. ${ }^{37}$

Although TNF $\alpha$ secretion pathways have been reported that are independent of TACE, ${ }^{38}$ most TNF $\alpha$ molecules are produced as cytoplasmic membrane proteins that are rapidly cleaved into a soluble form by TACE. ${ }^{39-41}$ The use of specific TACE inhibitors has been associated with progressive accumulation of TNF $\alpha$ on the surface of the cytoplasmic membrane of $\mathrm{TNF} \alpha$ producing cells, allowing for their specific and unequivocal identification. ${ }^{27}$ Such TACE inhibitor compounds do not affect secretion of cytokines other than TNF $\alpha$ into the extracellular medium, thus allowing cells to respond under conditions that mimic those occurring in vivo. Interestingly, it should be noted that despite the fact that up to 5$10 \%$ of all TNF $\alpha$ was still secreted in a soluble form, no unexpected reactivity for TNF $\alpha$ was observed on cells that would not respond to the stimuli used.

A major goal of our study was to show the feasibility of simultaneously measuring $\mathrm{TNF} \alpha^{+}$cells and quantify the amount of specific cytokines secreted by these cells. For this purpose, we used commercially available fluorescent beads coupled with cytokine-specific monoclonal antibodies. These cytokine-capture beads have been optimized to be used in cell-free body fluids such as the plasma and they have proven to be comparable to conventional ELISA assays ${ }^{42}$ with the advantage of allowing the simultaneous quantification of multiple cytokines in small sample volumes. In the present study, we clearly show that these cytokine-capture beads could also be used to precisely quantify cytokines in whole blood-stimulated samples, at the same time the number and phenotype of $\mathrm{TNF} \alpha^{+}$cells is evaluated. As shown in the present study, distinction between beads and cells could easily be made due to their uniquely different light scatter properties. At the same time, we could measure cellular $\mathrm{TNF} \alpha$ and one or more soluble cytokines. Interestingly, despite the relatively high amounts of several soluble cytokines accumulated at the extracellular level, no reactivity for these cytokines was detected on cells. Sequential analysis of cytokine responses to either PMA/ionomycin or LPS stimulation 
showed that, at least in these two models, surface TNF $\alpha$ was clearly detected prior to soluble IL6 and IFN $\gamma$, respectively. These results would support previous findings indicating that $\mathrm{TNF} \alpha$ is the first cytokine to be produced by stimulated $\mathrm{T}$ cells ${ }^{28}$ and extend this concept also to the monocytes, at the same time they point out a potential advantage of the cellular assays.

The final step of our study was to prove the feasibility of quantifying multiple cytokines simultaneously with the detection of the activated cytokine-secreting cells in a single tube assay. Obviously, when more than one cytokine are simultaneously evaluated, no single time-point may be optimal for all cytokines assayed. ${ }^{28}$ Therefore, in the present study stimulation periods of 3 and $4 \mathrm{~h}$ were chosen for PMA/ionomycin- and LPSactivated samples as the most sensitive time-points for detecting $\mathrm{TNF} \alpha$-secreting $\mathrm{T}$ cells and $\mathrm{TNF} \alpha$ secreting monocytes, respectively. At these timepoints, variable levels of different cytokines were detected which could be linked to the number of $\mathrm{TNF} \alpha^{+}$cells simultaneously evaluated. Since the beads used can be coated with monoclonal antibody reagents of any specificity, in this assay quantification of soluble cytokines could also be potentially complemented or replaced by the measurement of other soluble proteins secreted by the activated cells (eg granzyme B). This possibility is particularly important because $\mathrm{TNF} \alpha$ is also produced by nonhematopoietic cells ${ }^{43}$ such as astrocytes, endothelial cells or smooth muscle cells, which secrete other mediators different from the cytokines analyzed here. The use of the bead array technology in which combinations of beads of different sizes and fluorescence properties can be mixed, makes it possible to increase the number of soluble proteins measured up to more than $100 .{ }^{44}$

Although we showed that this method could be used for the evaluation of immunological responses by peripheral blood cells against generic stimuli such as LPS and PMA/ionomycin, a major challenge would be to prove that it could also be applied to the study of T-cell-mediated antigen-specific immune responses. In line with this, in the present study based on an assay model for evaluating anti-CMVspecific immune responses, we proved that this method could also be used to distinguish precisely CMV-seropositive from CMV-seronegative individuals. In addition to the quantitative evaluation of the amount of different soluble T-helper (eg IFN $\gamma$ ) and inflammatory (eg IL6) cytokines, that could also be obtained though conventional multiple ELISA assays, we were able to identify the monocytes and T-cell subsets responsible for CMV-induced cytokine secretion. The possibility of using TNF $\alpha$ expression on the cell surface for the identification of cytokine-secreting cells is of particular interest, because it allows not only the identification of cytokine-secreting cells but also provides a unique opportunity to further investigate the phenotypic and functional characteristics of CMV-specific $\mathrm{T}$ cells through the use of 5 or more color flow cytometry assays or the specific purification of each of the $\mathrm{TNF} \alpha^{+}$cell subsets. Further studies, are necessary to prove its utility in the evaluation of other antigen-specific immune responses, particularly those aimed at monitoring vaccination against infectious agents or tumors.

In summary, in the present study we describe a new and simple flow-cytometry-based immunological method that could be used to monitor immune responses in whole blood samples under different physiological and pathological conditions, through the simultaneous identification and quantitation of several populations of cytokine-secreting cells and multiple cytokines secreted into the extracellular compartments by these cells.

\section{Acknowledgements}

This work was supported in part by grants from the 'Instituto de Salud Carlos III', Ministerio de Sanidad y Consumo (Spain), Red de mieloma múltiple y otras gammapatías (Contract Grant Number: G03/ 136) and from the Ministerio de Cieucia y Tecnologia (Contract Grant Number: SAF2002-03096).

\section{References}

1 Parkin J, Cohen B. An overview of the immune system. Lancet 2001;357:1777-1789.

2 Arai KI, Lee F, et al. Cytokines: coordinators of immune and inflammatory responses. Annu Rev Biochem 1990;59:783-836.

3 Paul WE, Seder RA. Lymphocyte responses and cytokines. Cell 1994;76:241-251.

4 Favre N, Bordmann G, Rudin W. Comparison of cytokine measurements using ELISA, ELISPOT and semi-quantitative RT-PCR. J Immunol Methods 1997; 204:57-66.

5 Mathey E, Pollard J, Armati P. In situ hybridization for cytokines in human tissue biopsies. Methods Mol Biol 2003;249:41-46.

6 Clerici M, Shearer GM. A TH1-TH2 switch is a critical step in the etiology of HIV infection. Immunol Today 1993;14:107-111.

7 Kinter AL, Poli G, Fox L, et al. HIV replication in IL-2stimulated peripheral blood mononuclear cells is driven in an autocrine/paracrine manner by endogenous cytokines. J Immunol 1995;154:2448-2459.

8 Merz H, Fliedner A, Orscheschek K, et al. Cytokine expression in T-cell lymphomas and Hodgkin's disease. Its possible implication in autocrine or paracrine production as a potential basis for neoplastic growth. Am J Pathol 1991;139:1173-1180.

9 Picker LJ, Singh MK, Zdraveski Z, et al. Direct demonstration of cytokine synthesis heterogeneity among human memory/effector $\mathrm{T}$ cells by flow cytometry. Blood 1995;86:1408-1419.

10 Street NE, Mosmann TR. Functional diversity of $\mathrm{T}$ lymphocytes due to secretion of different cytokine patterns. FASEB J 1991;5:171-177. 
11 Orme IM, Roberts AD, Griffin JP, et al. Cytokine secretion by CD4 T lymphocytes acquired in response to Mycobacterium tuberculosis infection. J Immunol 1993;151:518-525.

12 Espel E, Garcia-Sanz JA, Aubert V, et al. Transcriptional and translational control of TNF-alpha gene expression in human monocytes by major histocompatibility complex class II ligands. Eur J Immunol 1996;26:2417-2424.

13 Bueno C, Almeida J, Alguero MC, et al. Flow cytometric analysis of cytokine production by normal human peripheral blood dendritic cells and monocytes: comparative analysis of different stimuli, secretion-blocking agents and incubation periods. Cytometry 2001;46:33-40.

14 Nylander S, Kalies I. Brefeldin A, but not monensin, completely blocks CD69 expression on mouse lymphocytes: efficacy of inhibitors of protein secretion in protocols for intracellular cytokine staining by flow cytometry. J Immunol Methods 1999;224:69-76.

15 Jung T, Schauer U, Heusser C, et al. Detection of intracellular cytokines by flow cytometry. J Immunol Methods 1993;159:197-207.

16 Manz R, Assenmacher M, Pflüger E, et al. Analysis and sorting of live cells according to secreted molecules, relocated to a cell-surface affinity matrix. Proc Natl Acad Sci USA 1995;92:1921-1925.

17 Waldrop SL, Davis KA, Maino VC, et al. Normal human $\mathrm{CD}^{+}$memory $\mathrm{T}$ cells display broad heterogeneity in their activation threshold for cytokine synthesis. J Immunol 1998;161:5284-5295.

18 Verhasselt V, Buelens C, Willems F, et al. Bacterial lipopolysaccharide stimulates the production of cytokines and the expression of costimulatory molecules by human peripheral blood dendritic cells: evidence for a soluble CD14-dependent pathway. J Immunol 1997;158:2919-2925.

19 Suni MA, Picker LJ, Maino VC. Detection of antigenspecific T cell cytokine expression in whole blood by flow cytometry. J Immunol Methods 1998;212:89-98.

20 Nomura LE, Walker JM, Maecker HT. Optimization of whole blood antigen-specific cytokine assays for CD4 ${ }^{+}$ T cells. Cytometry 2000;40:60-68.

21 Mandy F, Brando B. Enumeration of absolute cell counts using immunophenotypic techniques. In: Robinson JP, Darzynkiewicz Z, Dean PN (eds). Current Protocols in Cytometry. Wiley: New York, 2000, pp 6.8.1-6.8.26.

22 Dalton WS. The tumor microenvironment: focus on myeloma. Cancer Treat Rev 2003;29:11-19.

23 Whiteside TL. Immune responses to malignancies. J Allergy Clin Immunol 2003;111:S677-686.

24 Slifka MK, Whitton JL. Clinical implications of dysregulated cytokine production. J Mol Med 2000; 78:74-80.

25 Engleman EG. Dendritic cell-based cancer immunotherapy. Semin Oncol 2003;30:23-29.

26 Ribas A, Butterfield LH, Glaspy JA, et al. Current developments in cancer vaccines and cellular immunotherapy. J Clin Oncol 2003;21:2415-2432.

27 Bueno C, Rodríguez-Caballero A, García-Montero A, et al. A new method for detecting TNF- $\alpha$-secreting cells using direct-immunofluorescence surface membrane stainings. J Immunol Methods 2002;264:77-87.
28 Mascher B, Schlenke P, Seyfarth M. Expression and kinetics of cytokines determined by intracellular staining using flow cytometry. J Immunol Methods 1999;223:115-121.

29 Walker D, Jason J, Wallace K, et al. Spontaneous cytokine production and its effect on induced production. Clin Diagn Lab Immunol 2002;9:1049-1056.

30 Matthes $\mathrm{T}$, Werner-Favre $\mathrm{C}$, Tang $\mathrm{H}$, et al. Cytokine mRNA expression during an in vitro response of human B lymphocytes: kinetics of B cell tumor necrosis factor alpha, interleukin (IL)6, IL-10, and transforming growth factor beta 1 mRNAs. J Exp Med 1993;178:521-528.

31 Ohlsson K, Linder C, Lundberg E, et al. Release of cytokines and proteases from human peripheral blood mononuclear and polymorphonuclear cells following phagocytosis and LPS stimulation. Scand J Clin Lab Invest. 1996;56:461-470.

32 Plotz SG, Lentschat A, Behrendt $H$, et al. The interaction of human peripheral blood eosinophils with bacterial lipopolysaccharide is CD14 dependent. Blood 2001;97:235-241.

33 Abraham SN, Arock M. Mast cells and basophils in innate immunity. Semin Immunol 1998;10:373-381.

34 Hara T, Jung LKL, Bjorndahl JM, et al. Human $\mathrm{T}$ cell activation III. Rapid induction of a phosphorylated $28 \mathrm{wkD} / 32 \mathrm{kD}$ disulfide-linked early activation antigen (EA 1) by 12-O-tetradecanoyl phorbol-13acetate, mitogens, and antigens. J Exp Med 1986;164: 1988-2005.

35 López-Cabrera M, Santis AG, Fernandez-Ruiz E, et al. Molecular cloning, expression, and chromosomal localization of the human earliest lymphocyte activation antigen AIM/CD69, a new member of the C-type animal lectin superfamily of signal transmitting receptors. J Exp Med 1993;178:537-547.

36 Ziegler SF, Ramsdell F, Aldersson MR. The activation antigen CD69. Stem Cells 1994;12:456-465.

37 Waldrop SL, Davis KA, Maino VC, et al. Normal human $\mathrm{CD}^{+}$memory $\mathrm{T}$ cells display broad heterogeneity in their activation threshold for cytokine synthesis. J Immunol 1998;161:5284-5295.

38 Lunn CA, Fan X, Dalie B, et al. Purification of ADAM 10 from bovine spleen as a TNF $\alpha$ convertase. FEBS Lett 1997;400:333-335.

39 Arribas J, Coodly L, Vollmer P, et al. Diverse cell surface protein ectodomains are shed by a system sensitive to metalloprotease inhibitors. J Biol Chem 1996;271:11376-11382.

40 Black RA, Rauch CT, Kozlosky CJ, et al. A metalloproteinase disintegrin that releases tumor necrosis factor- $\alpha$ from cells. Nature 1997;385:729-733.

41 Moss ML, Jin SL, Milla ME, et al. Cloning of disintegrin metalloproteinase that processes tumor necrosis factor- $\alpha$. Nature 1997;385:733-736.

42 Chen R, Lowe L, Wilson JD, et al. Simultaneous quantification of six human cytokines in a single sample using microparticle-based flow cytometric technology. Clin Chem 1999;45:1693-1694.

43 Vilcek J, Lee TH. Tumor necrosis factor. J Biol Chem 1991;266:7313-7316.

44 Fulton RJ, McDade RL, Smith PL, et al. Advanced multiplexed analysis with the FlowMetrix ${ }^{\mathrm{TM}}$ system. Clin Chem 1997;43:1749-1756. 